\title{
Estimating Zonal Electricity Supply Curves in Transmission-Constrained Electricity Markets
}

\author{
Mostafa Sahraei-Ardakani*, Seth Blumsack**, Andrew Kleit** \\ *School of Electrical, Computer, and Energy Engineering, Arizona State University \\ **John and Willie Leone Family Department of Energy and Mineral Engineering, \\ The Pennsylvania State University
}

Corresponding author: Seth Blumsack, Department of Energy and Mineral Engineering, 124 Hosler Building, University Park PA, 16802. Tel: +1 (814) 863-7597. E-mail: sab51@psu.edu

Keywords: carbon tax; demand response policy; electricity markets; Pennsylvania's act 129; transmission constraints; zonal electricity supply curve

\begin{abstract}
Many important electricity policy initiatives would directly affect the operation of electric power networks. This paper develops a method for estimating short-run zonal supply curves in transmission-constrained electricity markets that can be implemented quickly by policy analysts with training in statistical methods and with publicly available data. Our model enables analysis of distributional impacts of policies affecting operation of electric power grid. The method uses fuel prices and zonal electric loads to determine piecewise supply curves, identifying zonal electricity price and marginal fuel. We illustrate our methodology by estimating zonal impacts of Pennsylvania's act 129, an energy efficiency and conservation policy. For most utilities in Pennsylvania, act 129 would reduce the influence of natural gas on electricity price formation and increase the influence of coal. The total resulted savings would be around 267 million dollars, 82 percent of which would be enjoyed by the customers in Pennsylvania. We also analyze the impacts of imposing a $\$ 35 /$ ton tax on carbon dioxide emissions. Our results show that the policy would increase the average prices in PJM by 47 to 89 percent under different fuel price scenarios in the short run, and would lead to short-run interfuel substitution between natural gas and coal.
\end{abstract}

\section{Introduction}

Many energy and environmental policy initiatives (including emissions regulations; renewable portfolio standards; and efficiency policies) would affect the operation of electric power grid. 
Analysis of such policies is however difficult in the absence of reliable models of the electric power system. The North American power transmission grid has been called "the largest and most complex machine in the world" [1]. Detailed modeling of the system requires complete engineering data on every element of the system such as transmission lines, transformers and generators. This engineering approach is often not feasible in the context of policy analysis due to the proprietary nature of the data and engineering model complexity. Moreover, policy analysis involves the study of future scenarios. Thus, the inputs to the model should be estimated for the future, which always involves some degree of uncertainty. Since the engineering models need detailed data, the set of input uncertainties becomes extremely large. There exist, many other methods in the literature for forecasting short term electricity prices, including probabilistic estimation of price duration curves [2], short term forecast with fuzzy neural networks [3-4], transfer functions [5], and linear and nonlinear time series[6-9]. These methods are designed to forecast short term prices from hours to a week ahead. They estimate short-term prices well but cannot be used in policy analysis, where acceptable performance over longer periods of time is needed. Abstract equilibrium models such as [10] can provide insights into strategic gaming and market design efficiency, but cannot be directly applied to real markets.

As a result, many policy models in the existing literature neglect the effects of the transmission system and use the relatively simple dispatch curve models [11-19]. In order to construct a dispatch curve, power plants in a system are sorted according to their marginal cost. The data needed for calculating marginal cost includes heat rate, fuel type and capacity, which are publically available through e-GRID [20] or other similar data sources. Fig. 1 shows an estimated dispatch curve for Pennsylvania-New Jersey-Maryland interconnection (PJM) and is calculated similar to [13]. PJM currently serves all or parts of Delaware, Illinois, Indiana, Kentucky, Mary- 
land, Michigan, New Jersey, North Carolina, Ohio, Pennsylvania, Tennessee, Virginia, West Virginia and the District of Columbia. Given data on electricity demand, the dispatch curve can be utilized to determine the marginal unit in the system, as well as the market price in the absence of transmission constraints (the so-called "System Marginal Price"). However, because of the transmission constraints, both prices and marginal technologies can be potentially different at different locations within the power system. For example in PJM during the peak hours prices are much higher in eastern areas such as Philadelphia and Washington, D.C. than Western Pennsylvania and West Virginia. At such times, coal may be on the margin in the western PJM while oil is on the margin in eastern PJM.

Locational price differences induced by transmission congestion can introduce challenges in the context of policy analysis. We take as an example Pennsylvania's Act 129, which is an energy conservation and efficiency policy that requires the state's utilities to reduce their annual demand by one percent with $4.5 \%$ additional peak demand shaving. ${ }^{1}$ By looking at the dispatch curve in Fig. 1, one can see that the slope of the supply curve is low when the demand is less than $250 \mathrm{GWh}$, and a policy analyst assessing the price impact of Act 129 would predict that the Act would not materially reduce wholesale prices in the PJM system (and, consequently, in Pennsylvania). Such an assessment would ignore important locational price differences, with two potential consequences. First, the estimated potential impacts of an efficiency policy such as Act 129 are likely to be biased downwards, since they would not capture the steeper supply curves (higher-cost generation) used in locations downstream from transmission constraints. Second, the policy analyst would not be able to estimate locational differences in price impacts and fuels utilization. These locational impacts may be important outcomes of the policy.

${ }^{1}$ The full text of Act 129 can be found online at http://www.puc.state.pa.us/electric/pdf/Act129/HB2200-Act129_Bill.pdf 
Fig. 1 suggests that, for a year similar to 2008, we can differentiate the technologies in the supply curve and find thresholds based on demand levels, where the marginal input fuel switches. While, the benefits and costs of fracking is unclear and under debate [21], it has significantly decreased the natural gas prices. Resulting shifts in relative fuel prices in the PJM region, (Fig. 2), have led in some short-run substitution of coal with natural gas technologies [22], as the marginal cost of efficient combined-cycle gas plants declines to levels similar to that of coal fired plants. Therefore, the threshold defining the border between coal and natural gas becomes fuzzy, as shown in Fig. 1 for 2010. In the fuzzy region, the marginal technology is effectively fueled by a mixture of coal and natural gas. Further changes in relative fuel prices (which may be caused by additional declines in natural gas prices or increases in coal prices) will serve to widen this fuzzy region, which means that a mixture of coal and natural gas will be marginal over a wider range of load.

\section{8}
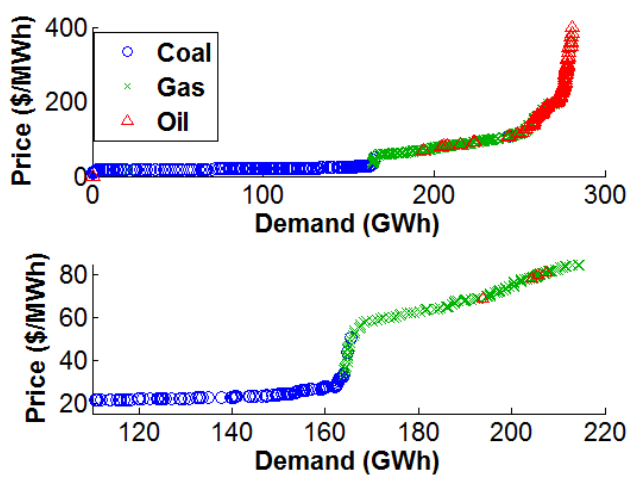

2010
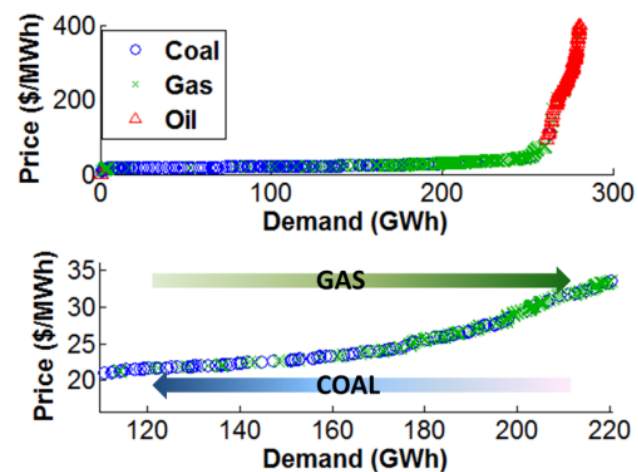

Fig. 1. Top-Left: Dispatch curve for PJM using the following fuel prices: Coal: \$50/t, Gas: \$8/MMBTU, Oil: $\$ 87 / \mathrm{bbl}$. This set of prices is similar to the situation in late 2008; Bottom-Left: The supply curve from 120 to 220 GWh of demand. This shows the transition from coal to natural gas more clearly. Right-Top: Dispatch curve for PJM using the following fuel prices: Coal: \$50/t, Gas: \$3/MMBTU, Oil: \$116/bbl. Increases in the price of coal relative to natural gas price results in a region where a mixture of coal and gas is marginal; Right-Bottom: The same curve is shown for the region representing 120 to $220 \mathrm{GWh}$ of demand. It shows how a mixture of two fuels is marginal when demand is between 120 and $200 \mathrm{GWh}$. These curves are estimated using heat rate data from eGrid [20] combined with assumptions of fuel prices. The heat content of coal and oil is assumed to be $25 \mathrm{MMBTU} / \mathrm{t}$ and 5.8 MMBTU/bbl respectively. 
Here we seek to develop a model with publicly available data that can capture locational differences in technologies and fuels that are on the margin in transmission-constrained electricity systems. Our method implicitly models transmission constraints by estimating electricity price and marginal fuel at the zonal level as a function of zonal and system-level electricity demand. (Large-scale power systems are often divided into geographic "zones" for planning, pricing or other purposes; see [23]). The rest of this paper is organized as follows: A simple example which motivates our method is presented in section 2. Our econometric model is described in section 3. Section 4 presents the application of our method to seventeen utility zone of PJM as well as the simulation of Pennsylvania Act 129 and a carbon tax policy. Section 5 concludes the paper.

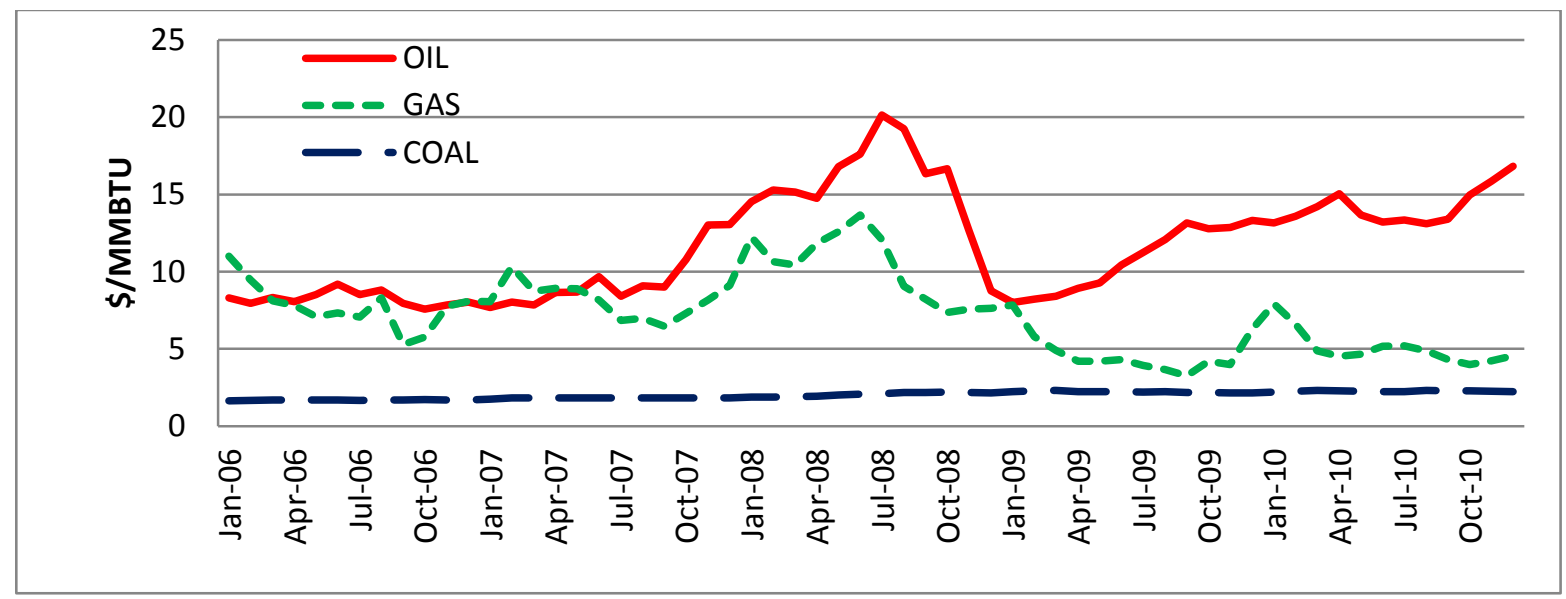

Fig. 2. Fuel price trends since January 2006.

\section{Motivating Example}

The following example shows how transmission constraints introduce complexities in building supply curves and performing policy analysis. Fig. 3 shows a simple electric system with two nodes. There is a single generator and single customer or "load" at each node. The generators are assumed to have simple linear marginal cost functions; $M C\left(G_{l}\right)=5+G_{l}$ for the genera- 
tor at node 1 , and $M C\left(G_{2}\right)=10+2 G_{2}$ for the generator at node 2 . For the purposes of this example, we will ignore any capacity constraints on the two generators but we will assume that the transmission line connecting the two nodes has a capacity limit of 20 Megawatts (MW). If demand at node 1 in a certain hour is given by $L_{1}=30 \mathrm{MWh}$ and demand at node 2 is given by $L_{2}=$ $35 \mathrm{MWh}$, then total demand in the system is $L=65 \mathrm{MWh}$ and there is no transmission congestion. The supply curve for the system is thus the vertical sum of the individual supply curves: $G$ $=1.5 P-10$ for $G>5$, where $G=G_{1}+G_{2}$ and $P$ is the market price of electricity. At a demand of $65 \mathrm{MWh}$, we thus have $65=1.5 P-10$, and the market-clearing price for electricity is $\$ 50 / \mathrm{MWh}$. Under this scenario, $G_{1}=45 \mathrm{MWh}$ and $G_{2}=20 \mathrm{MWh}$. Thus, $15 \mathrm{MWh}$ of electric energy is transferred across the transmission line from node 1 to node 2. A policy that, for example, would reduce demand at node 2 by $10 \mathrm{MWh}$ would reduce the market-clearing price for all consumers in the system to $\$ 43.3 / \mathrm{MWh}$.

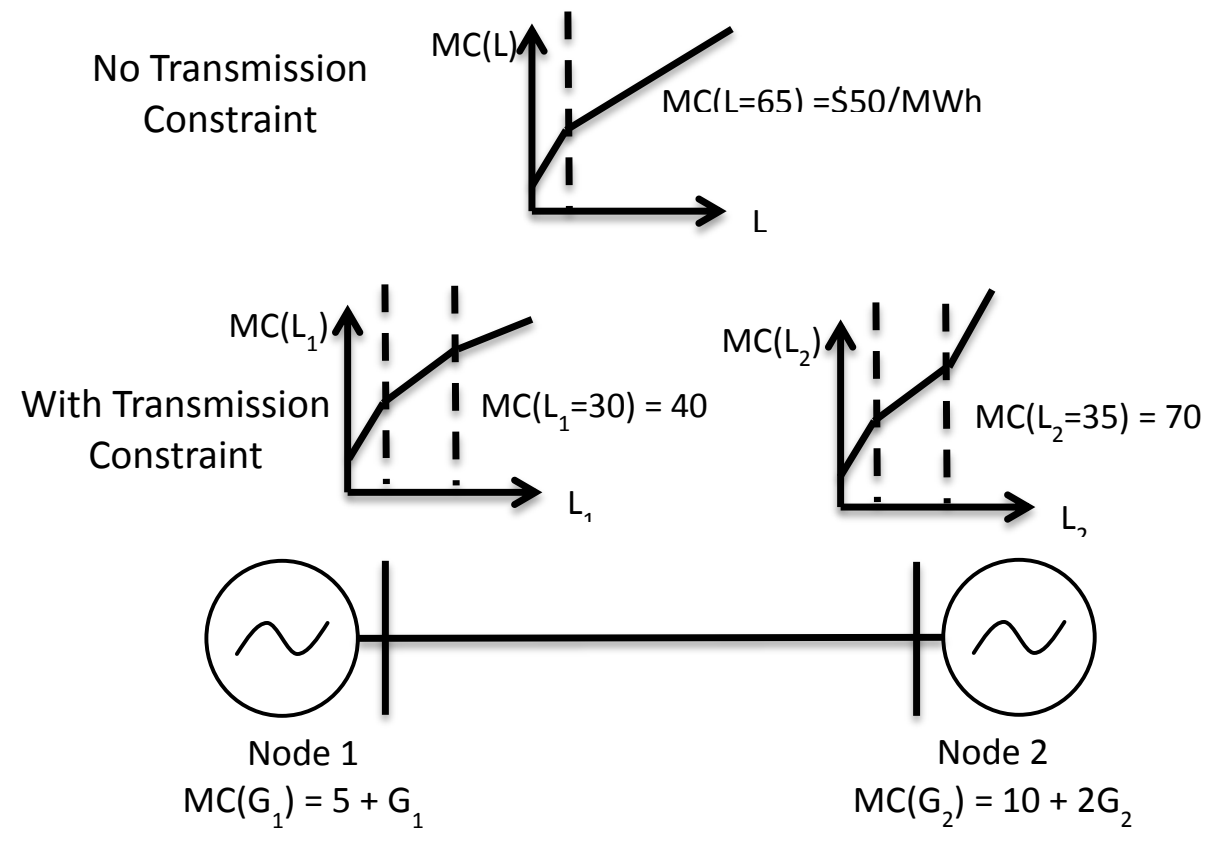


Fig. 3. Without transmission congestion, there is a single system-wide supply curve and a single system-wide market price. The presence of transmission congestion segments the market, so that Nodes 1 and 2 effectively have different supply curves and different locational market prices.

At higher levels of demand, however, the transmission constraint prevents some lower-cost generation from being delivered across the transmission line. Higher-cost generation, local to the downstream node, must be dispatched instead. This introduces kinks into the supply curve for each location; the location of the kinks depends on both the demand at the specific location and the aggregate demand at all locations in the network. The "out-of-merit" dispatch of power generators in the presence of transmission congestion segments the electricity market into two zonal sub-markets, each of which have their own supply curve and their own clearing price. These prices are, in essence, the Locational Marginal Prices (LMP) used in most organized wholesale markets in the United States. Using our example in Fig. 3, considering a transmission limit of $20 \mathrm{MW}$, the marginal cost functions to supply electricity at each node are given by Equation 1.

$$
\begin{aligned}
\text { (1a) } M C_{1}\left(L_{1}, L_{2}\right) & =\left\{\begin{array}{lc}
\frac{2\left(L_{1}+L_{2}\right)+20}{3} & \text { if }-20 \leq \frac{-L_{1}+2 L_{2}+5}{3} \leq 20 \\
5+\left(L_{1}+20\right) & \text { if } \frac{-L_{1}+2 L_{2}+5}{3}>20 \\
5+\left(L_{1}-20\right) & \text { if } \frac{-L_{1}+2 L_{2}+5}{3}<-20
\end{array}\right. \\
\text { (1b) } M C_{2}\left(L_{1}, L_{2}\right) & =\left\{\begin{array}{lc}
\frac{2\left(L_{1}+L_{2}\right)+20}{3} & \text { if }-20 \leq \frac{-L_{1}+2 L_{2}+5}{3} \leq 20 \\
10+2\left(L_{2}-20\right) & \text { if } \frac{-L_{1}+2 L_{2}+5}{3}>20 \\
10+2\left(L_{2}+20\right) & \text { if } \frac{-L_{1}+2 L_{2}+5}{3}<-20
\end{array}\right.
\end{aligned}
$$

Determining each of these supply curves for a two-node example is tractable in closed form, even if the network is transmission-constrained. Realistic networks, however, are more complex and far less tractable. The example demonstrated how transmission constraints affect supply 
curves at different locations of the system. It should be noted that, transmission constraints are much more complicated in realistic meshed networks and we do not use this simplistic limit in the rest of the paper.

\section{Methodology}

When the system is constrained, different fuels can set the electricity price in various zones. For each zone we call this fuel "zonal marginal fuel". For each zone, first we identify this zonal marginal fuel as a function of the zonal demand, system-wide demand and relative fuel prices. Then we assign a separate segment of the zonal supply curve to each fuel type that depends only on the relevant fuel price and load. The zonal marginal fuel is estimated based on a membership function that identifies the influence of a certain fuel price on the price of electricity for each observation. Our approach is to minimize the sum of squared errors in the following equation:

$$
\text { (2) } \quad p_{i k}=\sum_{j=1}^{J} M_{j i}\left(q_{i k}, q_{T k}, \vec{\varphi}_{j i}, \vec{p}_{i k}^{F}\right) S F_{j i}\left(q_{i k}, q_{T k}, \vec{\omega}_{j i}, p_{j i k}^{F}\right)+e_{i k}
$$

The subscript $i$ represents the zone $i, j$ indicates the fuel $j$, and $k$ is the index of the observation. $M_{j}$ is the membership function specifying the influence of fuel $j$ on the price in zone $i . p_{i k}$ is the zonal electricity price, $\vec{p}_{i k}^{F}$ is the vector of zonal fuel prices and $q_{i k}$ is the zonal load. For the sake of simplicity we use $q_{T k}=\sum_{i} q_{i k}$ in our formulation to account for demand in other zones of the market. $S F_{i j}$ is the partial supply function regarding fuel $j$ at zone $i . \vec{\varphi}_{j i}$ and $\vec{\omega}_{j i}$ are the parameter vectors for $M$ and $S F$ functions and $e_{i k}$ is the error term for the observation $k$ at zone $i$.

By estimating equation (2) separately for each zone, we are able to capture the zonal price and fuel utilization differences resulting from transmission congestion. For our simulation studies we chose $j=3$ to include coal, natural gas and oil, the three major marginal fuels in PJM 
(While PJM uses substantial amounts of nuclear power, this technology is not marginal in the PJM system and therefore never sets the price). Since we estimate fuzzy membership functions the three segments of the supply curve can potentially overlap. We refer to this area of overlap as the "fuzzy band." The membership functions $M_{j i}$ should satisfy the following conditions:

$$
\text { (3) }\left\{\begin{array}{l}
0 \leq M_{j i} \leq 1 \\
\sum_{j=1}^{J} M_{j i}=1
\end{array}\right.
$$

Equation (3) states the probability principles for the membership functions. The probability of each fuel being marginal is between 0 and 1 , and they sum to 1 over all the fuels. We may thus rewrite equation (2) as:

$$
\begin{aligned}
& p_{e i}\left(q_{i}, q_{T}, p_{C i}, p_{G i}, p_{O i}\right)=M_{C i}\left(q_{i}, q_{T}, p_{C i}, p_{G i}\right) S F_{C i}\left(q_{i}, q_{T}, p_{C i}\right)+ \\
& \quad M_{G i}\left(q_{i}, q_{T}, p_{C i}, p_{G i}, p_{O i}\right) S F_{G i}\left(q_{i}, q_{T}, p_{G i}\right)+M_{O i}\left(q_{i}, q_{T}, p_{G i}, p_{O i}\right) S F_{O i}\left(q_{i}, q_{T}, p_{O i}\right)
\end{aligned}
$$

Where $p_{e i}$ is the price of electricity and $p_{C i}, p_{G i}$ and $p_{O i}$ are the prices of coal, gas, and oil. $S F_{C i}, S F_{G i}$, and $S F_{O i}$ are the parts of supply function associated with fuels coal, gas, and oil, $M_{C i}$, $M_{G i}$, and $M_{O i}$ are the membership functions indicating how much coal, gas, or oil is on the margin. All these variables are considered at zone $i$. In order to use Equation (4), the $S F$ and $M$ functions need to be specified. We use quadratic supply curves as shown in Equation (5).

$$
\text { (5) } S F_{j i}\left(q_{i}, q_{T}, p_{j i}\right): p_{e i}=\alpha_{0 j i} p_{j i}+\alpha_{1 j i} p_{j i} q_{i}+\alpha_{2 j i} p_{j i} q_{i}^{2}+\beta_{1 j i} p_{j i} q_{T}+\beta_{2 j i} p_{j i} q_{T}^{2}
$$

where $\alpha$ and $\beta$ parameters are the supply function coefficients. As the notation suggests, fuel prices can differ on a zonal basis. Equation (5) implies that electricity price is a quadratic function of electrical load, while the coefficients of the function can vary by fuel prices. 
In addition to the piecewise supply function we need to assign fuzzy membership functions to each observation. In our model, the mean of the fuzzy band is fixed based on quantities, and the width of the gap is a function of relative fuel prices. As described in Fig. 4, the fuzzy membership functions linearly increase or decrease in the fuzzy band from 0 to 1 . The width of the fuzzy band depends on the relative fuel prices, as shown in Equation (6) for the case of the fuzzy band between coal and natural gas.

$$
\begin{gathered}
\Delta_{C / G}=I\left(\frac{P_{C}}{P_{G}}-T_{P_{C}}^{*}\right) \cdot \gamma_{C / G} \cdot\left(\frac{P_{C}}{P_{G}}-T_{P_{C}}^{*}\right) \\
I(x)= \begin{cases}1 & x \geq 0 \\
0 & x<0\end{cases}
\end{gathered}
$$

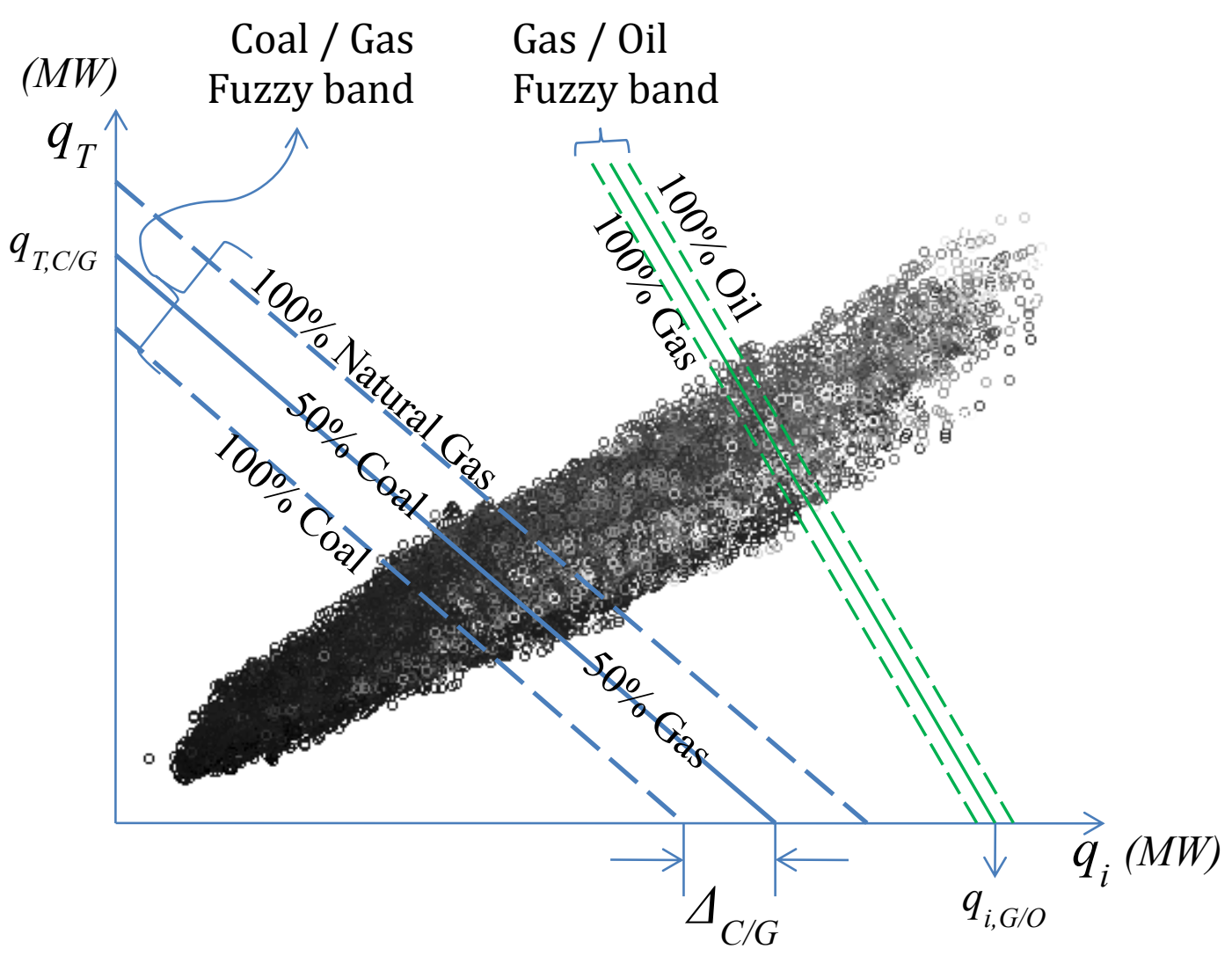

Fig. 4. Fuzzy variable thresholds: The fuzzy band depends on the relative fuel prices while the mean of the distribution is a fixed line in $q_{i}-q_{T}$ space. 
In Equation (6), $P_{C}$ is the price of coal, $P_{G}$ is the price of natural gas and $\frac{T_{P_{C}}}{P_{G}}$ is the minimum relative price (i.e., the price of coal relative to the price of gas) needed for the existence of a fuzzy band. For relative prices below this limit, our probabilistic model becomes similar to the model described and used in [24-26], where the thresholds separating segments of the supply curve are defined by deterministic lines. The term $\gamma_{C / G}$ specifies how the fuzzy band widens when the relative prices increase. We can write the same equation for the transition from gas to oil as shown in Equation 7.

$$
\text { (7) } \Delta_{G / O}=I\left(\frac{P_{G}}{P_{O}}-T_{\frac{P_{G}}{P_{O}}}^{*}\right) \cdot \gamma_{G / O} \cdot\left(\frac{P_{G}}{P_{O}}-T_{\frac{P_{G}}{P_{O}}}^{*}\right)
$$

Thus to fully identify the fuzzy thresholds we need to find $q_{i, C / G}, q_{i, G / O}, q_{T, C / G}, q_{T, G / O}, \frac{T_{C}}{P_{G}}$, $\gamma_{C / G}, T_{\frac{P_{G}}{P_{O}}}^{*}$ and $\gamma_{G / O}$. Once these parameters are specified we can use an ordinary least squared (OLS) regression method to estimate the parameters in Equation (5). To minimize the sum of squared errors in Equation (2), we need to find the optimal parameters for the fuzzy threshold. Estimation of the membership functions' parameters is an optimization problem with the objective of minimizing the sum of squared errors. With different threshold parameters, the set of observations belonging to a specific fuel would change. However, marginal perturbation of the threshold parameters would likely not change such sets. Thus, the objective function has a stepwise shape, with billions of steps and flat regions, making it non-linear, non-differentiable, and non-convex. Moreover, our examinations show that the objective function is multi-modal with multiple local minima. Therefore, classical optimization algorithms fail to handle the problem. We use a powerful evolutionary optimization algorithm known as Covariance Matrix Adaptation-Evolution Strategy (CMA-ES). It takes samples from the decision space and approximates 
the covariance matrix from the fitness of the samples. In the first step of the algorithm, a number of individual solutions (sets of parameter estimates) are generated. In each generation, OLS is used to estimate the $\omega$ parameters (see Equation 2) for each individual solution. Then the sum of squared errors is calculated and fed back to CMA-ES as the fitness of each solution. The fitness values are used to rank individuals and generate the next generation of parameters for the membership functions. This process is repeated until the stopping criteria are met [27-28].

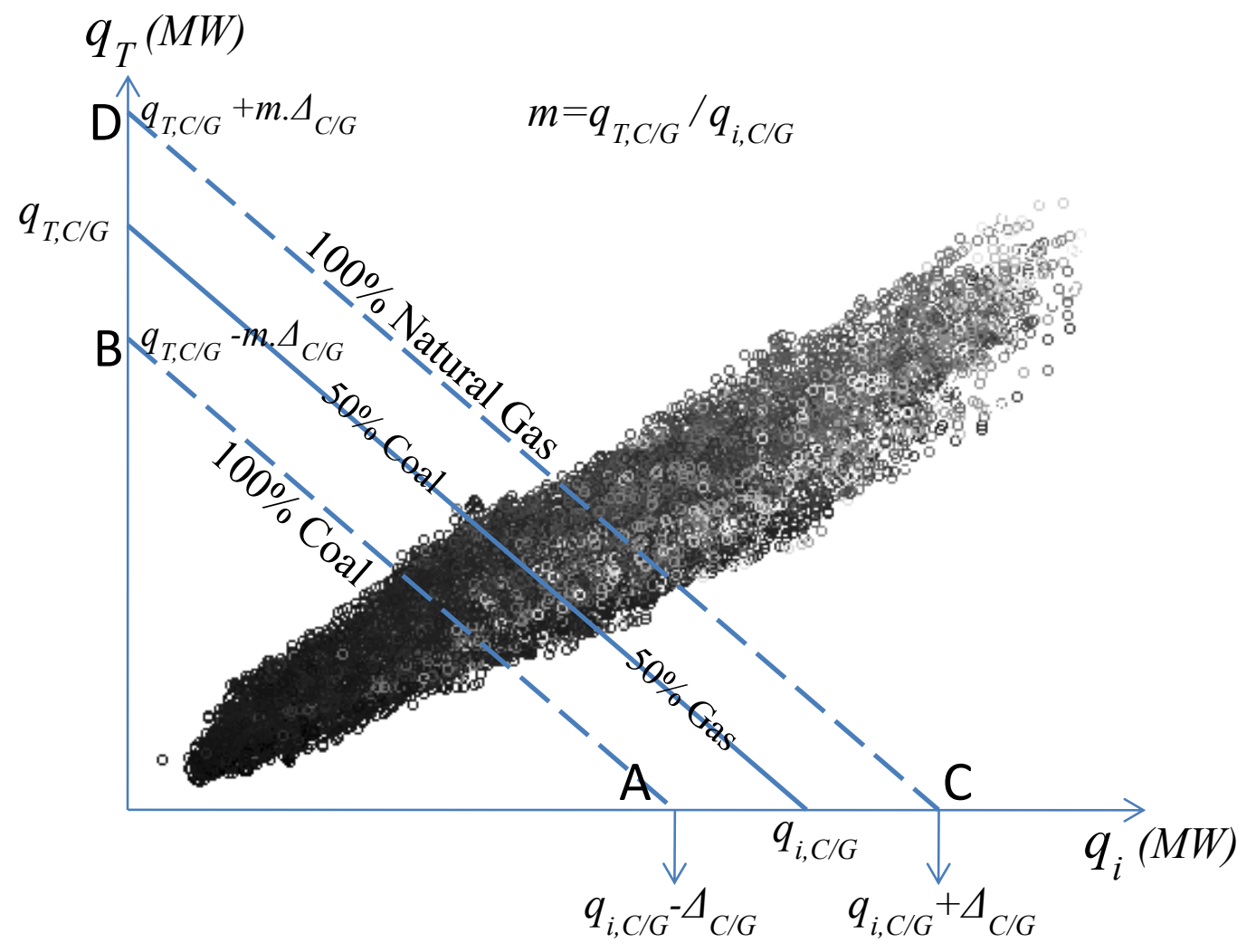

Fig. 5. Fuzzy membership function assignment for coal using analytical geometry formulation for linear plane.

After specifying all eight parameters needed for the fuzzy thresholds we use them to assign membership functions to the data points. While the width of the fuzzy band depends on relative fuel prices (and thus may vary from observation to observation), we assume that the mean of the fuzzy band (the solid lines in Fig. 4) is fixed based on own area and PJM loads. Fig. 5 shows 
how the fuzzy membership function for coal is defined. At points A and B, the membership function gives the value of 1 , while at points $\mathrm{C}$ and $\mathrm{D}$, the function has the value of zero. The membership function is a linear plane fitting the four points. According to analytical geometry we only need three points to specify the plane. The plane's formulation is given in Equation (8):

$$
\begin{aligned}
& \left|\begin{array}{ccc}
q_{i}-q_{i}^{A} & q_{T}-q_{T}^{A} & M_{C}^{\prime}-M_{C}^{A} \\
q_{i}^{B}-q_{i}^{A} & q_{T}^{B}-q_{T}^{A} & M_{C}^{B}-M_{C}^{A} \\
q_{i}^{C}-q_{i}^{A} & q_{T}^{C}-q_{T}^{A} & M_{C}^{C}-M_{C}^{A}
\end{array}\right|=0 \\
& A:\left[\begin{array}{c}
q_{i, C / G}-\Delta_{C / G} \\
0 \\
1
\end{array}\right] \quad B:\left[\begin{array}{c}
0 \\
q_{T, C / G}-m . \Delta_{C / G} \\
1
\end{array}\right] \quad C:\left[\begin{array}{c}
q_{i, C / G}+\Delta_{C / G} \\
0 \\
0
\end{array}\right] \\
& \underset{\text { Replacing } A, B, C}{\longrightarrow}\left|\begin{array}{ccc}
q_{i}-\left(q_{i, C / G}-\Delta_{C / G}\right) & q_{T} & M_{C}{ }^{\prime}-1 \\
-\left(q_{i, C / G}-\Delta_{C / G}\right) & q_{T, C / G}-m \cdot \Delta_{C / G} & 0 \\
2 \Delta_{C / G} & 2 m \cdot \Delta_{C / G} & -1
\end{array}\right|=0
\end{aligned}
$$

$M_{C}{ }^{\prime}$ is the unadjusted membership function for coal. The formulation provided in Equation (8) gives negative values for points outside the upper bound of the fuzzy band. It also gives values larger than one for observations outside the lower bound of the fuzzy band. We constrain such estimates to lie on the upper or lower bound of the fuzzy band, as shown in Equation (9)

$$
\text { (9) } M_{C}=\left\{\begin{array}{cc}
1 & M_{C}^{\prime}>1 \\
M_{C}^{\prime} & 0 \leq M_{C}^{\prime} \leq 1 \\
0 & M_{C}^{\prime}<0
\end{array}\right.
$$

The membership function for oil is calculated in a similar fashion. We force the fuzzy bands for coal/gas and for gas/oil to be disjoint. This is not necessary but it is consistent with the PJM system, where coal and oil would not be simultaneously on the margin. The membership function for natural gas is calculated in Equation (10).

$$
M_{G}=1-M_{C}-M_{O}
$$


Implementation of our method also requires adjustment of the price when estimating zonal electricity prices within the fuzzy band. This is due to the fact that summation of coal and gas parts of the supply curve, in the fuzzy region, would result in a higher price than the price influenced by the mixture of the two fuels. We address this issue by adjusting zonal and system loads within the fuzzy band to bound electricity price estimates from above. Our mechanism for bounding price estimates in this way is described in detail in Appendix A.

\section{Simulation Studies}

We used zonal load and real time electricity prices obtained from the PJM website. We also gathered state level fuel prices for electricity industry from the U.S. Energy Information Administration. Our data is from January 2006 to December 2010. The method explained in previous section is utilized to estimate supply curves for each of the seventeen utility zones of $\mathrm{PJM}^{2}$. A map of PJM is depicted in Fig. 6. The utility names with their abbreviations are presented in Table 1 .

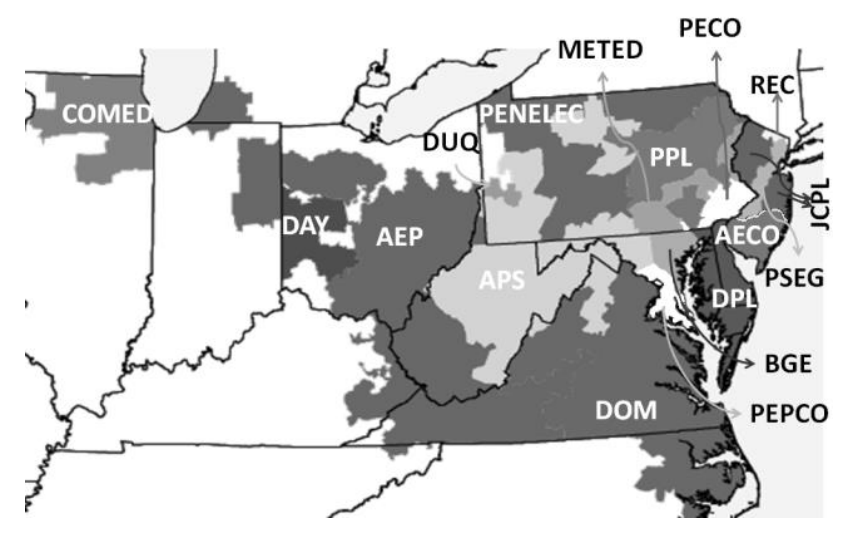

Fig. 6. Geographical distribution of utilities in PJM electricity market

Table 1

PJM utility names and abbreviation

\begin{tabular}{|l|l|l|l|}
\hline Utility Name & Abbr. & Utility Name & Abbr. \\
\hline
\end{tabular}

\footnotetext{
${ }^{2}$ Estimated Membership function and regression parameters, are available within the request from the
} authors. 


\begin{tabular}{|l|l|l|l|} 
Allegheny Power Systems & APS & Jersey Central Power and Light Company & JCPL \\
\hline American Electric Power & AEP & Metropolitan Edison Company & METED \\
\hline Atlantic City Electric Company & AECO & Philadelphia Electric Company & PECO \\
\hline Baltimore Gas and Electric Company & BGE & Pennsylvania Power and Light & PPL \\
\hline Commonwealth Edison Company & COMED & Pennsylvania Electric Company & PENELEC \\
\hline Dayton Power and Light Company & DAY & Potomac Electric Power Company & PEPCO \\
\hline Dominion & DOM & Public Service Electric and Gas Company & PSEG \\
\hline Delmarva Power and Light Company & DPL & Rockland Electric Company & RECO \\
\hline Duquesne Light & DUQ & & \\
\hline
\end{tabular}

With the estimated membership function and regression parameters, we can construct the zonal supply curves and use them for policy analysis. The results show that a fuzzy coal/natural gas region exists when the price of coal is more than 1.1 to 1.3 times the price of natural gas for various zones ${ }^{3}$. The thresholds are depicted for Dominion (DOM) in Fig. 7, in which we can see the areas where different fuels are marginal.

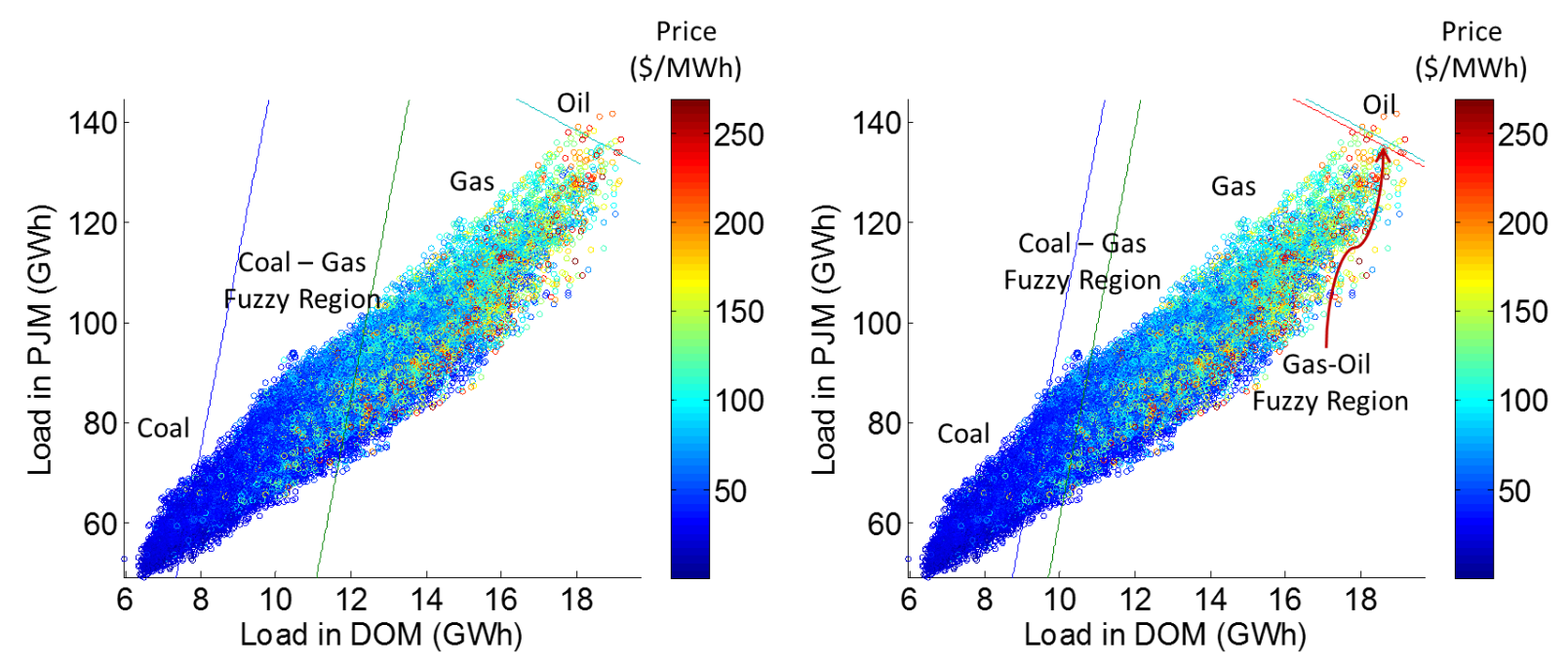

Fig. 7. Left: fuzzy thresholds in Dominion assuming fuel prices of $\$ 2.25 / \mathrm{mmBTU}$ for coal, $\$ 5 /$ Thousand cubic feet for gas and $\$ 15 / \mathrm{mmBTU}$ for oil. This set of fuel prices would result in a deterministic threshold between natural gas and oil. Right: fuzzy thresholds in Dominion assuming fuel prices of $\$ 2 / \mathrm{mmBTU}$ for coal, \$10/Thousand cubic feet for gas and $\$ 20 / \mathrm{mmBTU}$ for oil.

${ }^{3}$ Complete information on the estimated supply curves is available within the request from the authors. 
We use our zonal supply curve to simulate the impacts of two policies in PJM. We first simulate the effects of imposing a carbon tax on electric generation. Then we study the impacts of Pennsylvania Act 129 on utility zones in Pennsylvania and other PJM states.

\subsection{Carbon Tax}

The representative emissions of $\mathrm{CO}_{2}$ produced from each fuel per billion BTU of energy are as follows: 94.35 tons for coal; 53.07 tons for natural gas; and 74.39 tons for oil. Each thousand cubic feet of natural gas contains 1.03 MMBTU of energy. With the data on carbon emission by fuel, we can calculate the equivalent fuel prices considering the carbon tax.

$$
\begin{gathered}
P_{\text {Coal }}^{\text {Tax }}=P_{\text {Coal }}+0.094 \times \text { Tax }_{\text {Carbon }} \quad\left(\frac{\$}{m m B T U}\right) \\
P_{\text {Gas }}^{\text {Tax }}=P_{\text {Gas }}+0.054 \times \text { Tax }_{\text {Carbon }} \quad\left(\frac{\$}{\text { Thousand qubic feet }}\right) \\
P_{\text {Oil }}^{\text {Tax }}=P_{\text {Oil }}+0.074 \times \text { Tax }_{\text {Carbon }} \quad\left(\frac{\$}{m m B T U}\right)
\end{gathered}
$$

$P^{T a x}$ represents the fuel price including the carbon tax. Tax ${ }_{C a r b o n}$ has the unit of $\$ /$ Ton of $\mathrm{CO}_{2}$. British Columbia has implemented a carbon tax of $\$ 30 /$ ton and comparable taxes are proposed for Washington State [29]. Here, we study the impacts of imposing a carbon tax in the similar range as in $\mathrm{BC}, \$ 35$ per ton of $\mathrm{CO} 2$, under two fuel price scenarios: a high natural gas price scenario similar to [13] and a low natural gas price similar to fall 2010. For both scenarios we assume price elasticity of demand to be -0.1 [30]. The fuel prices under each scenario are presented in table 2 .

Table 2

Fuel prices under the two scenarios

\begin{tabular}{lll}
\hline & High gas price scenario [13] & Low gas price scenario (Fall 2010) \\
\hline Coal (\$/MMBTU) & 1.73 & 2.25 \\
Natural Gas (\$MMBTU) & 9.95 & 4 \\
Oil (\$/MMBTU) & 8.49 & 15 \\
\hline
\end{tabular}


The estimated effects of a $\$ 35$ per ton of $\mathrm{CO}_{2}$ tax on zonal electricity prices in PJM are shown in table 3. Lower gas prices shift some of the efficient gas plants to the left side of the supply curve to serve the base load. This means that more coal fired power plants would be used for serving shoulder load. Therefore coal would gain more influence in setting the electricity prices (i.e., coal would be the marginal fuel more often). Imposing a carbon tax would make coal more expensive relative to natural gas. When coal is on the margin more frequently, the carbon tax would further increase the price of electricity. Table 3 shows that under the low gas price scenario the average prices would increase by 89 percent while the same tax would increase prices by 47 percent under a high gas price scenario. Our estimates of overall price increases are somewhat higher than [13], which estimated the price increase to be 40 percent over all of PJM under a scenario with high natural gas prices. The model in [13], however, is not able to differentiate location-specific price increases, which we estimate to be between 27 percent and 84 percent.

Table 3

Average prices before and after imposing a carbon tax of $\$ 35$ per ton under the two scenarios $(\$ / \mathrm{MWh})$

\begin{tabular}{lrrr|rrr}
\hline & \multicolumn{3}{c|}{ Low gas price scenario } & \multicolumn{3}{c}{ High gas price scenario } \\
\cline { 2 - 7 } APS & No Tax & Tax & \% Change & No Tax & Tax & \% Change \\
AEP & 36.13 & 63.13 & 74.76 & 60.95 & 89.07 & 46.15 \\
AECO & 31.94 & 66.44 & 107.99 & 45.87 & 77.92 & 69.87 \\
BGE & 38.55 & 63.18 & 63.89 & 69.56 & 92.15 & 32.47 \\
COMED & 40.99 & 134.80 & 228.87 & 71.31 & 95.17 & 33.46 \\
DPL & 28.15 & 47.93 & 70.29 & 50.66 & 70.72 & 39.59 \\
DUQ & 39.80 & 64.66 & 62.45 & 71.12 & 94.77 & 33.26 \\
JCPL & 32.56 & 61.61 & 89.24 & 45.78 & 80.95 & 76.81 \\
METED & 40.41 & 80.21 & 98.49 & 62.58 & 98.00 & 56.61 \\
PECO & 39.91 & 62.86 & 57.52 & 64.19 & 95.36 & 48.55 \\
PPL & 38.58 & 62.58 & 62.21 & 61.30 & 92.38 & 50.70 \\
PENELEC & 37.12 & 73.21 & 97.20 & 55.64 & 90.13 & 61.98 \\
PEPCO & 38.08 & 70.41 & 84.92 & 74.18 & 94.20 & 26.99 \\
PSEG & 38.08 & 72.40 & 90.14 & 68.50 & 92.20 & 34.60 \\
RECO & 36.84 & 66.82 & 81.38 & 67.73 & 90.18 & 33.15 \\
\hline
\end{tabular}




\begin{tabular}{lllr|rrr}
\hline DAY & 32.74 & 91.92 & 180.75 & 42.43 & 78.23 & 84.39 \\
DOM & 37.78 & 60.26 & 59.52 & 74.42 & 97.21 & 30.63 \\
PJM & $\mathbf{3 5 . 3 2}$ & $\mathbf{6 7 . 0 5}$ & $\mathbf{8 9 . 5 2}$ & $\mathbf{5 9 . 8 9}$ & $\mathbf{8 6 . 6 3}$ & $\mathbf{4 7 . 1 5}$ \\
\hline
\end{tabular}

The carbon tax policy would also change fuels utilization. Table 4 presents our estimates of how often each fuel is on the margin in each zone of PJM. Under a low gas price scenario, the carbon tax would shift more low-cost natural gas to serving base-load demand. Under a high gas price scenario, the carbon tax induces similar fuel-switching, but to a lesser extent in most zones than under the low gas price scenario. Under the high gas price scenario we estimate 7.2 percent reductions in $\mathrm{CO}_{2}$ emissions across PJM, while [13] estimated a 10.6 percent reduction. We estimate 12.35 percent $\mathrm{CO}_{2}$ reduction under the low gas price. When the gas prices are low, coal fired plants shift from base load to shoulder load and play a more important role in setting the electricity prices. Therefore carbon tax would have a larger effect on electricity prices when natural gas prices are low.

Our model estimates higher price increases and lower emission reductions compared to the transmission-less model [13]. When transmission constraints are taken into the consideration, some expensive units (likely gas fired power plants) would be used before some cheaper units (likely coal fired plants). Those coal fired plants that would have been used to serve the base load, would now be used to serve the shoulder load. Therefore, the resulting out-of-merit dispatch would shift some of the coal plants to the right hand side of the supply curve, leading to increased influence of coal on the electricity prices. The more often coal sets the price, the more the electricity price will increase as a result of a carbon tax policy.

Table 4

The frequency with which, each fuel is marginal before and after the carbon tax $(\%)$. 


\begin{tabular}{ccccccc|cccccc}
\hline \multicolumn{1}{c}{ Coal } & \multicolumn{4}{c|}{ Natural Gas } & \multicolumn{2}{c}{ Oil } & \multicolumn{3}{c}{ Coal } & \multicolumn{3}{c}{ Natural Gas } \\
APS & 45.72 & 55.47 & 54.04 & 44.53 & 0.25 & 0.00 & 47.37 & 55.66 & 52.36 & 44.30 & 0.27 & 0.05 \\
AEP & 58.66 & 61.45 & 41.34 & 38.55 & 0.00 & 0.00 & 65.61 & 70.97 & 34.39 & 29.03 & 0.00 & 0.00 \\
AECO & 35.64 & 49.16 & 63.10 & 50.78 & 1.26 & 0.06 & 29.98 & 43.54 & 68.37 & 55.86 & 1.65 & 0.61 \\
BGE & 42.68 & 49.77 & 56.34 & 50.23 & 0.97 & 0.00 & 41.50 & 46.71 & 57.53 & 53.17 & 0.97 & 0.11 \\
COMED & 42.66 & 53.21 & 57.34 & 46.79 & 0.00 & 0.00 & 41.53 & 51.88 & 58.47 & 48.12 & 0.00 & 0.00 \\
DPL & 36.47 & 48.11 & 61.23 & 51.64 & 2.30 & 0.25 & 31.64 & 42.52 & 65.80 & 56.31 & 2.57 & 1.17 \\
DUQ & 60.22 & 62.75 & 39.78 & 37.25 & 0.00 & 0.00 & 70.24 & 72.82 & 29.76 & 27.18 & 0.00 & 0.00 \\
JCPL & 33.38 & 48.66 & 65.13 & 51.32 & 1.49 & 0.02 & 27.45 & 41.00 & 71.05 & 58.73 & 1.49 & 0.27 \\
METED & 52.32 & 55.85 & 47.68 & 44.15 & 0.00 & 0.00 & 55.81 & 60.54 & 44.19 & 39.46 & 0.00 & 0.00 \\
PECO & 43.87 & 54.65 & 54.00 & 45.19 & 2.13 & 0.17 & 43.59 & 53.92 & 53.96 & 45.06 & 2.45 & 1.02 \\
PPL & 45.41 & 55.61 & 52.45 & 44.26 & 2.14 & 0.13 & 46.17 & 55.65 & 51.49 & 43.51 & 2.35 & 0.84 \\
PENELEC & 54.41 & 58.47 & 45.59 & 41.53 & 0.00 & 0.00 & 61.17 & 65.36 & 38.83 & 34.64 & 0.00 & 0.00 \\
PEPCO & 29.79 & 45.77 & 69.19 & 54.23 & 1.02 & 0.00 & 23.91 & 37.13 & 74.87 & 62.57 & 1.22 & 0.30 \\
PSEG & 35.03 & 48.82 & 63.32 & 51.12 & 1.66 & 0.06 & 29.57 & 42.63 & 68.38 & 56.61 & 2.05 & 0.77 \\
RECO & 31.74 & 47.30 & 66.52 & 52.62 & 1.75 & 0.08 & 25.88 & 39.40 & 72.14 & 59.93 & 1.97 & 0.66 \\
DAY & 64.73 & 61.87 & 35.27 & 38.13 & 0.00 & 0.00 & 80.98 & 76.28 & 19.02 & 23.72 & 0.00 & 0.00 \\
DOM & 34.48 & 46.37 & 65.46 & 53.63 & 0.06 & 0.00 & 35.04 & 41.68 & 64.89 & 58.32 & 0.06 & 0.00 \\
\hline
\end{tabular}

We estimated the changes in producers' surplus for all plants in the system (assuming that nuclear power plants in the PJM system are always operating at maximum capacity, and neglecting hydroelectric and wind energy), and for fossil plants only. Under a low gas price scenario, the total change would create around 4.1 billion dollars in surplus in a year while the fossil plants lose around 7.6 billion dollars in surplus (the difference represents increases in producer surplus enjoyed by nuclear power). Under a high gas price scenario, the total changes would create around 5.7 billion dollars, while the fossil plants lose 4.4 billion dollars in surplus.

The estimated supply curves for APS and JCPL under the low gas price scenario are depicted in Fig. 8. In PJM, the prices are higher in eastern parts (e.g. JCPL) where there is a larger demand. In the western PJM (e.g. APS), there are cheaper power plants but the electricity cannot be exported to the eastern PJM due to the congestion in transmission lines. 

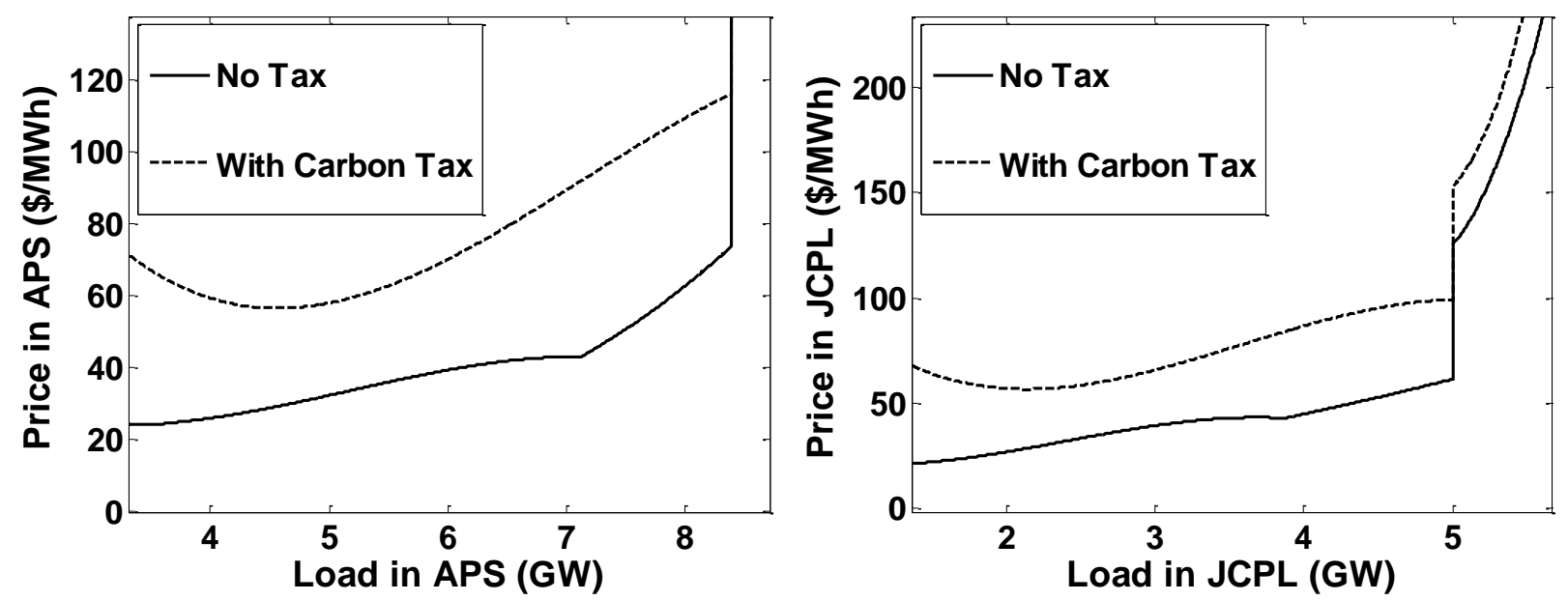

Fig. 8. Projected supply curve for APS, in central Pennsylvania and West Virginia, and JCP, in New Jersey.

\subsection{Pennsylvania's Act 129}

We use our method of estimating zonal supply curves in the PJM market to evaluate the impacts of Act 129, implemented in Pennsylvania in 2009. Act 129 requires utilities in Pennsylvania to cut their annual electrical load by 1 percent, with additional load reductions amounting to 4.5 percent during the 100 highest-load hours each year. We apply our supply curve estimation method to simulate the impacts of Act 129 on zonal electricity costs in PJM, the frequency with which each fuel is on the margin in each PJM zone, and the emissions of greenhouse gases by power generators in the PJM system. We compare our results with those obtained from a single system dispatch curve model that ignores transmission constraints [13]. Our analysis uses 2010 as a base year, so annual and peak-time load reductions are measured relative to 2010 electricity demand in PJM. We generate hourly electricity demands under Act 129 using the following procedure:

1. For each hour in our 2010 data set, we determine the relative amount of total PJM demand that represents Pennsylvania utilities.

2. Each hour's demand is reduced by 1 percent. 
3. In the top 100 hours of demand, each hour's demand is reduced by an additional 4.5 percent.

Given our new set of hourly PJM demands, adjusted to reflect successful implementation of Act 129 , hourly market-clearing prices and generator dispatch are obtained by determining the intersection between the short-run supply curve and a vertical demand curve at each hour's level of demand. The same procedure is used to obtain hourly market-clearing prices and generator dispatch for our baseline case, based on the PJM market in 2010.

Our estimates of Act 129's impact generated using the single dispatch curve model projects that total electricity costs in the PJM territory would decline by $\$ 150$ million on an annual basis following the successful implementation of Act 129. Using plant-level average emissions data from the e-GRID database, we calculate that Act 129 reduces annual carbon dioxide emissions in the PJM territory by 2.9 million tons. For simplicity, we assumed that APS meets Act 129 demand reduction goals in its entire territory. The fuel prices in our estimation are the ones presented as the low gas price scenario (Table 2).

Table 5

Savings from Pennsylvania Act 129 in PJM's utility zones. The units are in millions of dollars.

\begin{tabular}{lllll}
\hline Utility Zone & Without Act 129 & With Act 129 & Saved & Percentage Saved \\
\hline APS & 1833.07 & 1790.44 & 42.64 & 2.33 \\
AEP & 4602.33 & 4586.17 & 16.17 & 0.35 \\
AECO & 500.19 & 496.34 & 3.85 & 0.77 \\
BGE & 1533.36 & 1531.61 & 1.75 & 0.11 \\
COMED & 3052.06 & 3048.98 & 3.09 & 0.10 \\
DPL & 840.46 & 837.74 & 2.72 & 0.32 \\
DUQ & 501.93 & 492.97 & 8.96 & 1.78 \\
JCPL & 1005.66 & 991.47 & 14.19 & 1.41 \\
METED & 670.16 & 664.56 & 5.60 & 0.84 \\
PECO & 1823.39 & 1748.68 & 74.70 & 4.10 \\
PPL & 1661.50 & 1611.37 & 50.12 & 3.02 \\
PENELEC & 700.15 & 685.12 & 15.02 & 2.15 \\
PEPCO & 1364.51 & 1360.96 & 3.55 & 0.26 \\
\hline
\end{tabular}




\begin{tabular}{lllll}
\hline PSEG & 1914.82 & 1902.89 & 11.92 & 0.62 \\
RECO & 63.52 & 62.87 & 0.65 & 1.03 \\
DAY & 605.70 & 604.59 & 1.11 & 0.18 \\
DOM & 3944.99 & 3933.25 & 11.74 & 0.30 \\
PJM & $\mathbf{2 6 6 1 7 . 8 0}$ & $\mathbf{2 6 3 5 0 . 0 1}$ & $\mathbf{2 6 7 . 7 9}$ & $\mathbf{1 . 0 1}$ \\
Pennsylvania & $\mathbf{8 3 8 8 . 2 7}$ & $\mathbf{8 1 8 8 . 0 4}$ & $\mathbf{2 0 0 . 2 3}$ & $\mathbf{2 . 3 9}$ \\
\hline
\end{tabular}

Analysis of Act 129 using our estimated zonal supply curves suggests that the energy cost savings in PJM would be $\$ 267$ million, about $\$ 200$ million of which would be enjoyed by electricity consumers in Pennsylvania. This implies that the total cost of electricity in Pennsylvania and territories of APS outside Pennsylvania would decline by 2.4 percent, while total costs within the PJM system as a whole would decline by around 1 percent. The zonal results are shown in Table 5. Our results are close to the estimates from an existing study of Act 129's impacts [31], which suggest that savings due to Act 129 amounted to $\$ 278$ million in 2011. Our estimates may be lower than those in [31] for two reasons. First, we assume a lower price for natural gas; and second, the magnitude of the demand reduction used in [31] is larger than ours (their assumed demand reduction is more than required under Act 129.)

The estimated impacts of Act 129 are uniformly larger using our regional supply curve estimation method than using the single dispatch curve method. Total estimated electricity cost savings are 78 percent larger. Using our regional supply curve estimation method, we find that 82 percent of the net benefit of Act 129 is enjoyed by Pennsylvania utilities and customers, in the form of lower electricity costs. When the single dispatch curve model is used, we cannot differentiate region-specific impacts.

\section{Conclusion}


Analysis of electricity policies often requires understanding the effects of transmission constraints, which can be very complex. Incorporating transmission-system in engineering models requires detailed information that is neither publicly available nor practical to use for many economists and policy analysts. Many existing analyses thus abstract from transmission constraints. While this assumption makes modeling more tractable, it can underestimate the impacts of electricity policies, sometimes by substantial margins. Moreover, abstraction from transmission constraints prevents the estimation of location-specific impacts. We develop a method to estimate zonal prices in a transmission-constrained electricity markets. Our method also estimates the marginal fuel based on zonal load and the total demand in the market. It can also detect when a mixture of two fuels is on the margin. Our model is particularly useful when the distributional impacts of a policy are of special interest.

We applied our model to the seventeen utility zones in the PJM footprint and calculated the fuzzy zonal thresholds where the marginal fuel switches. Our results show the sensitivity of the marginal fuel to the zonal and system loads. We found that the price of electricity in PJM is mostly driven by natural gas prices, although in some zones coal-fired power plants are on the margin during the majority of hours. We simulated a carbon tax of $\$ 35$ per ton in PJM and found that such a policy would increase the prices by 47 to 89 percent in PJM. Such a carbon tax would increase the influence of coal on formation of electricity prices and reduce the $\mathrm{CO}_{2}$ emissions by 7.2 to 10.6 percent. Our example analysis of Pennsylvania's Act 129 shows that compliance with Act 129 demand-reduction targets lowers total electric generation costs in Pennsylvania by 2.4 percent. We estimate the total cost reduction in PJM to be around 1 percent which translates to $\$ 267$ million. While the assumption that transmission constraints can be ignored 
makes policy models more tractable, our analysis of Pennsylvania Act 129 suggests that these models may underestimate the impacts of electricity policies.

In order to be able to construct this model, there is an essential need for data. It should be noted that, price and load data is not publically available for some power systems such as Southern Company. Moreover, similar to any statistical method, the accuracy of the results relies on the consistency of the historical data. Any significant structural change in the system, such as major new transmission lines, would affect the reliability of the model.

\section{Appendix: Correcting for Electricity Price Over-Estimation in the Fuzzy band}

For the sake of simplicity assume that the marginal fuel is just a function of zonal load. Moreover assume that the electricity price is a linear function of load in each segment. Fig. A1-a shows such a condition when the difference between natural gas and coal price is large enough that there is no overlap between segments of the zonal supply curve (the threshold between the coal and gas segments is a deterministic line). At the threshold the most expensive coal fired power plant sets the price at $p_{1}$. Now assume that natural gas prices drop to a lower level resulting in a fuzzy band between the coal and natural gas segments of the zonal supply curve. The price is still equal to $p_{1}$ but it could be set either by a high-cost coal plant with a marginal cost of $p_{1}$ at the relevant level of production, or a low-cost natural gas plant, also with a marginal cost of $p_{1}$ at the relevant level of production. This situation is shown in Fig. A1-b.

In the fuzzy band, either coal or gas could be the marginal fuel, but in either case the prevailing price should be $p_{1}$. The estimation problem arises when projecting the coal portion of the supply curve to the upper boundary of the fuzzy band. Within the fuzzy band, both the coal and gas segments of the supply curve would predict a price of $p_{1}$. But on the boundary of the fuzzy 
band the coal segment of the supply curve would predict a higher price. Fig. A1-c shows the coal segment of the supply curve in the fuzzy band. If we use the original supply function as we use it outside the fuzzy band we end up with the unadjusted projection shown in the Fig., and estimate an electricity price higher than $p_{l}$. This is clearly incorrect since the price of coal has not changed and thus the estimated price of electricity should not change. Thus, we need to adjust the supply function in the fuzzy region so that the price is bounded from above by $p_{1}$. To do so, we adjust the load variables $\left(q_{i}, q_{T}\right)$ in the fuzzy area, where a mixture of two fuels is marginal.

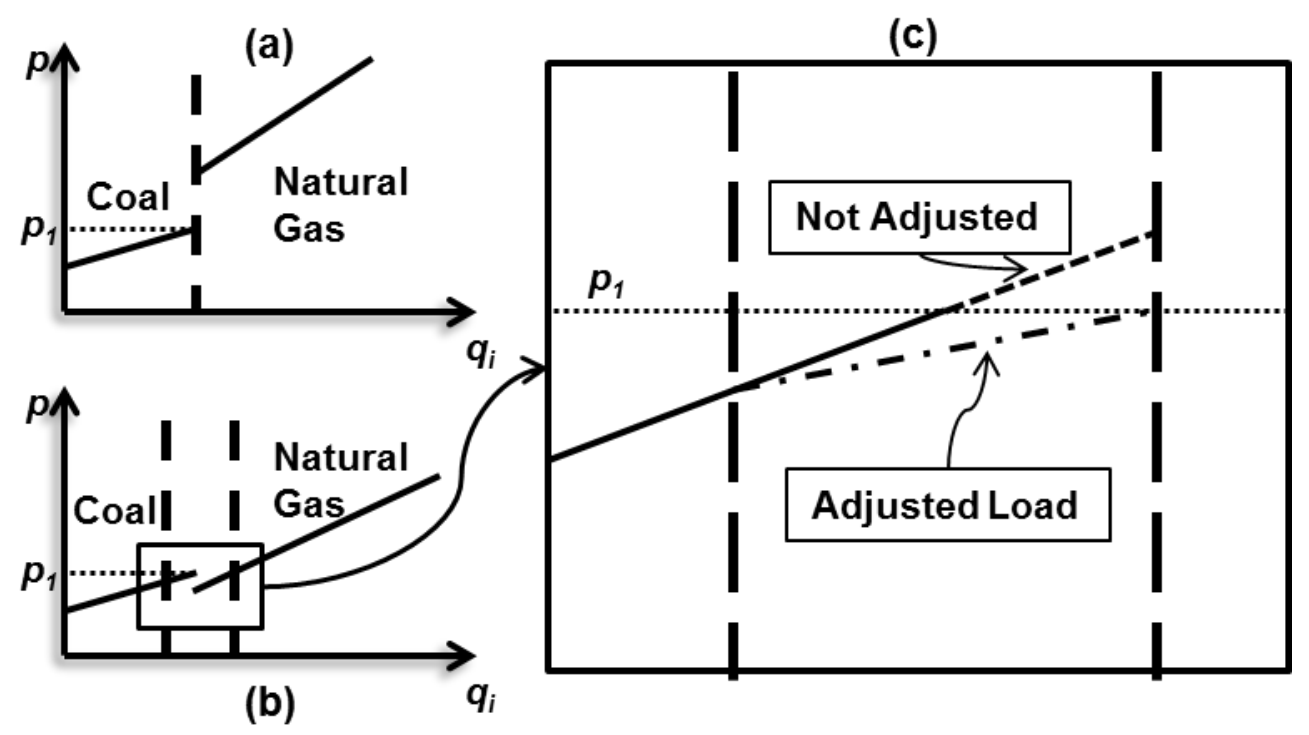

Fig. A1. An example explaining why we need to adjust the load variable in the fuzzy band. (a): Coal and gas segments of supply function, assuming deterministic marginal fuels. (b): The same supply functions assuming lower natural gas prices which results in a fuzzy area where a mixture of natural gas and coal is marginal. (c): The coal portion of the zonal supply curve in the fuzzy band. If we do not adjust the supply curve the estimated electricity price exceeds $p_{1}$.

Fig. A2 shows two different fuzzy bands for the coal-gas threshold, with widths $\Delta_{1}$ and $\Delta_{2}$. Points A, B and C represent the same marginal coal-fired power plant under three different fuzzy band scenarios. In the case with no fuzzy band (i.e., the membership functions are deterministic), point A represents the most expensive relevant coal power plant in the system. With the 
fuzzy band of width $\Delta_{1}$, point $\mathrm{B}$ represents the same power plant. Point $\mathrm{C}$ represents the same power plant when fuzzy band has a width of $\Delta_{2}$. Assuming a fixed coal price for all three of these cases, Equation (4) should estimate the same coal-related electricity price for all the three described cases. To do so we utilize a transformation to map point C (associated with a fuzzy band of width $\Delta_{1}$ ) and point B (fuzzy band of width $\Delta_{2}$ ) to the reference point A. Such a transformation should not, however, change the locations of the fuzzy band boundaries (represented by points $\mathrm{D}$ and $\mathrm{E}$ in Fig. A2).

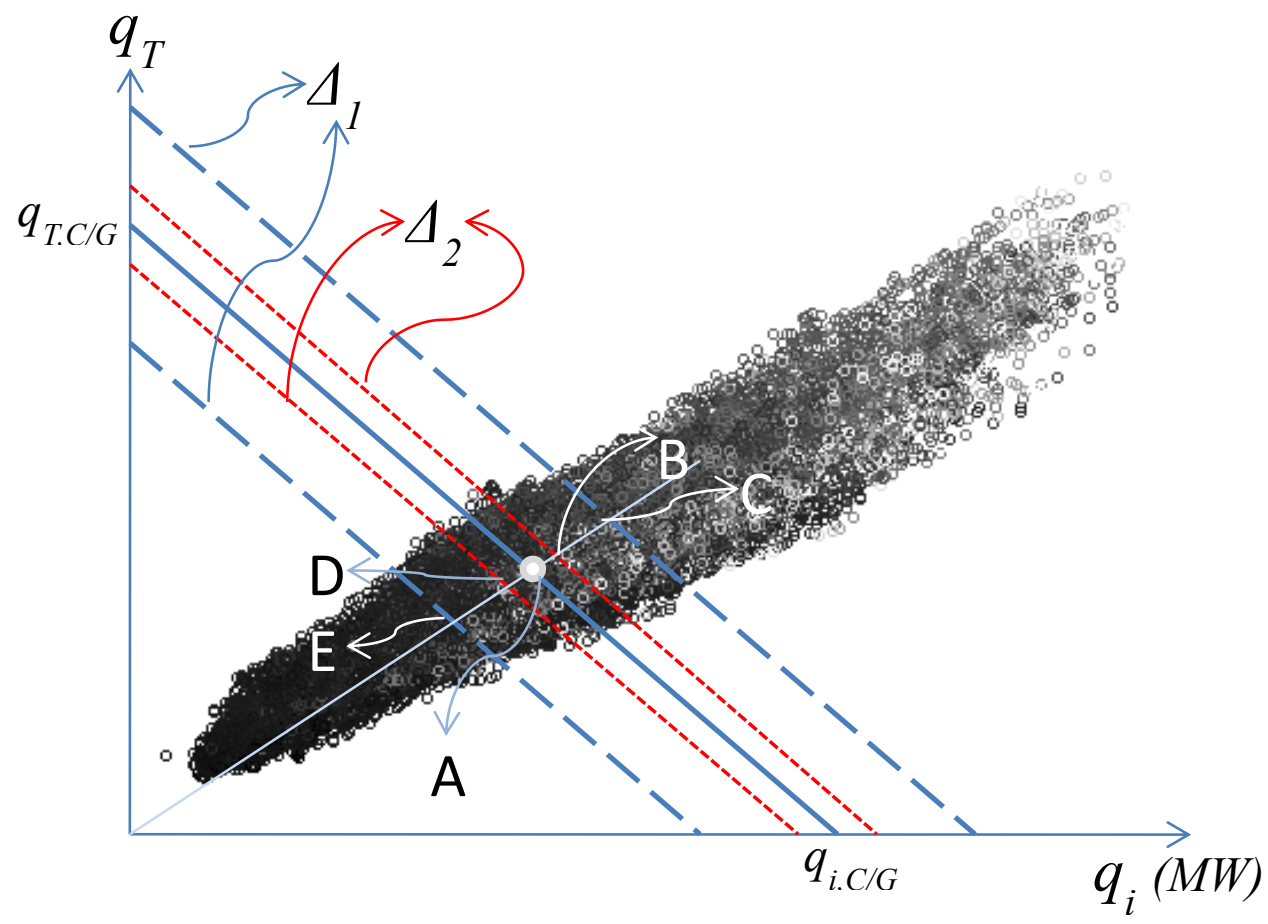

Fig. A2. Load adjustment in the fuzzy bands

The transformation for coal is explained by Equation (A1). $q_{i}^{C}$ and $q_{T}^{C}$ are the equivalent zonal and system load for coal part of the supply function. $q_{i}^{0}$ and $q_{T}^{0}$ are the projections of the original point on the lower fuzzy limit (E or D). Similar transformation is needed for gas and oil. For 
oil we need the projection on the higher limit of the fuzzy band. For natural gas, the projection depends on whether there is a mixture of coal and gas or gas and oil.

$(\boldsymbol{A 1})$

$$
0<M_{C}<1 \quad\left\{\begin{array}{l}
q_{i}^{C}=\frac{q_{i}^{0}+q_{i}}{2} \\
q_{T}^{C}=\frac{q_{T}^{0}+q_{T}}{2}
\end{array}\right.
$$

$$
q_{i}^{0}=\frac{q_{T, \frac{c}{G}}-\frac{q_{T, \frac{C}{G}}}{q_{i, \frac{C}{G}} \cdot \Delta_{\bar{G}}}}{\frac{q_{T}}{q_{i}}+\frac{q_{T, \frac{C}{G}}}{q_{i, \frac{C}{G}}}} q_{T}^{0}=\frac{q_{T}}{q_{i}} \cdot q_{i}^{0}
$$

\section{References}

[1] Masoud A. Balancing market priorities with security issues, IEEE Power and Energy Magazine 2004; 30-8.

[2] Valenzuela J, Mazumdar M. A probability model for the electricity price duration curve under oligopoly market. IEEE Transactions on Power Systems 2005;20(3):1250-6.

[3] Amjady N. Day-ahead price forecasting of electricity markets by a new fuzzy neural network. IEEE Transactions on Power Systems 2006;21(2):887-96.

[4] An N, Zhao W, Wang J, Shang D, Zhao E. Using multi-output feedforward neural network with empirical mode decomposition based signal filtering for electricity demand forecasting. Energy 2013;(49):279-88.

[5] Nogales FJ, Conejo AJ. Electricity price forecasting through transfer function models. Journal of the Operational Research Society 2006;(57):350-6.

[6] Amarawickrama HA, Hunt LC. Electricity demand for Sri Lanka: a time series analysis. Energy 2008;33(5):724-739.

[7] Pappas SS, Ekonomou L, Karamousantas DC, Chatzarakis GE, Katsikas SK, Liatsis P. Electricity demand loads modeling using AutoRegressive Moving Average (ARMA) models. Energy 2008;33(9):1353-60.

[8] McLoughlin F, Duffy A, Conlon M. Evaluation of time series techniques to characterize domestic electricity demand. Energy 2013;50:120-30.

[9] Misiorek A, Trueck S, Weon R. Point and interval forecasting of spot electricity prices: linear vs. non-linear time series models. Studies in Nonlinear Dynamics \& Econometrics 2006;10(3):1-36.

[10] Ruibal CM, Mazumdar M. Forecasting the mean and the variance of electricity prices in deregulated markets. IEEE Transactions on Power Systems 2008;23(1):25-32.

[11] Holland SP, Mansur ET. The short-run effects of time-varying prices in competitive electricity markets. Energy Journal 2006;27(4):127-55.

[12] Apt J, Blumsack SA, Lave LB. Competitive energy options for Pennsylvania," report for the Team Pennsylvania Foundation, 2007. Available at: 
http://wpweb2.tepper.cmu.edu/ceic/papers/Competitive_Energy_Options_for_Pennsylva nia.htm

[13] Newcomer A, Blumsack SA, Apt J, Lave LB, Morgan MG. Short run effects of a price on carbon dioxide emissions from US electric generators. Environmental Science \& Technology 2008;42(9):3139-44..

[14] Newcomer A, Apt J. Near-term implications of a ban on new coal-fired power plants in the United States. Environmental science \& technology 2009;43(11):3995-4001.

[15] Blumsack, S. Electric rate design and emissions reductions. In Proc. of IEEE Power and Energy Society General Meeting 2009, Calgary AB.

[16] Dowds J, Hines P, Farmer C, Watts R. Estimating the impact of electric vehicle charging on electricity costs given electricity-sector carbon cap. Transportation Research Record. Journal of the Transportation Research Board 2010:2191(1):43-9.

[17] Dowds J, Hines P, Blumsack S. Estimating the impact of fuel-switching between liquid fuels and electricity under electricity-sector carbon-pricing schemes. Socio-Economic Planning Sciences 2013;47(2):76-88.

[18] Borenstein S, Bushnell JB, Wolak FA. Measuring market inefficiencies in California's restructured wholesale electricity market. The American Economic Review 2002; 92(5):1376-404.

[19] Joskow P, and Kahn E. Identifying the exercise of market power: refining the estimates. Technical report 2001.

[20] US Environment Protection Agency. The Emissions \& Generation Resource Integrated Database (eGRID). Available at: www.epa.gov/egrid

[21] Fisk JM. The right to know? state politics of fracking disclosure. Review of Policy Research 2013;30(4):345-65.

[22] Holladay JS, LaRiviere J. The effect of abundant natural gas on air pollution from electricity production. Working Paper 2013.

[23] Sahraei-Ardakani M, Blumsack S, Kleit A. Zonal supply curve estimation in transmission-constrained electricity markets. Available at SSRN 2011; http://ssrn.com/abstract=1937411

[24] Sahraei-Ardakani M, Blumsack, SA, Kleit A. Distributional impacts of state-level energy efficiency policies in regional electricity markets. Energy Policy 2013; 49:365-72.

[25] Kleit A, Blumsack SA, Lei Z, Hutelmyer L, Sahraei-Ardakani S, Smith S. Impacts of electricity restructuring in rural Pennsylvania. The Center for Rural Pennsylvania 2011.

[26] Govindarajan A, Blumsack SA. Equilibrium modeling of combined heat and power deployment. In Proc. of $32^{\text {nd }}$ USAEE North American Conference, 2012.

[27] Hansen N, Muller S, Koumoutsakos P. Reducing the time complexity of the derandomized evolution strategy with covariance matrix adaptation (CMA-ES). Evolutionary Strategy 2003;11(1):1-18.

[28] Hansen N, Ostermeier A. Completely Derandomized Self-Adaptation in Evolution Strategies. Evolutionary Computation 2001;9(2):159-95.

[29] Schnoor, J. Responding to Climate Change with a Carbon Tax. Environmental science \& technology 2014.

[30] Spees K, and Lave L. Demand response and electricity market efficiency. The Electricity Journal 2007; 20(3):69-85. 
[31] PennFuture. Pennsylvania 2013-2018 Energy Efficiency Goals. 2011; Available at: http://www.pennfuture.org/UserFiles/File/FactSheets/Report_Act129goals_20111220.pd $\mathrm{f}$ 